\title{
Lobomyia neotropica, a new genus and species of Tachinidae (Diptera) from the Neotropical Region
}

\author{
NORMAN E. WOODLEY ${ }^{1} \&$ PAUL H. ARNAUD, JR. ${ }^{2}$ \\ ${ }^{1}$ Systematic Entomology Laboratory, PSI, ARS, USDA, \% Smithsonian Institution NHB-168, P O Box 37012, Washington, DC 20013- \\ 7012, USA e-mail: norman.woodley@ars.usda.gov \\ ${ }^{2}$ Department of Entomology, California Academy of Sciences, 875 Howard Street, San Francisco, CA 94103, USA. \\ E-mail: parnaud@calacademy.org
}

\begin{abstract}
A new genus and species, Lobomyia neotropica gen. nov., sp. nov., (Diptera: Tachinidae) is described from material from Colombia (type locality), Brazil, Costa Rica, Mexico, and Trinidad. The Colombian material was reared from Glena bisulca Rindge (Lepidoptera: Geometridae), a defoliator of introduced cypress trees. Costa Rican material was reared from several species of Lepidoptera: Notodontidae.
\end{abstract}

Key words: Diptera, Tachinidae, Lobomyia neotropica, new genus, new species, Neotropical Region

\section{Introduction}

The genus and species described herein has been known for several decades (Vélez 1974). The late Curtis Sabrosky was sent specimens for identification by biological control workers studying Glena bisulca Rindge (Lepidoptera: Geometridae), a serious cypress (Cupressus lusitanica Miller) defoliator in central Colombia (Drooz \& Bustillo 1972). He noted that the taxon belonged to a new genus and species, but never continued his work on the project. NEW began work to describe the species at the instigation of Sabrosky. Independently, the late W.R. Thompson knew of this species from a single specimen collected in Trinidad, and PHA recognized the taxon as new from material collected in Brazil by Fritz Plaumann and did some preliminary work toward describing it. Because of the potential for exotic Glena species to become invasive into the United States (Kliejunas et al. 2001), it is appropriate at long last to formally describe this taxon. It is also being described so that the generic name is available to be included in a manual of Central American Diptera that is nearing completion.

Lobomyia neotropica gen. nov., sp. nov. was first reported in the literature as "mosca verde" by Vélez (1974) from specimens reared from Glena bisulca by biological control workers in Colombia. The colloquial name referred to the bright green coloration of the living fly. Species of Glena, including G. bisulca, also are considered pests of Eucalyptus spp. in plantations in South America where they apparently have shifted from native Myrtaceae hosts. There is some concern that Eucalyptus feeders in South America could become invasive into the United States through importation of Eucalyptus logs and chips (Kliejunas et al. 2001).

\section{Material and methods}

Terminology follows McAlpine (1981). Label data are quoted verbatim for the holotype, with slashes "/" used 
to denote separate labels. Data for the paratypes are summarized in standardized format. Acronyms for institutions where specimens reside are as follows:

$\begin{array}{ll}\text { CAS } & \text { California Academy of Sciences, San Francisco, California, USA. } \\ \text { CNC } & \text { Canadian National Collection of Insects, Agriculture and Agri-Food Canada, Ottawa, } \\ \text { Ontario, Canada. } & \\ \text { DMW } & \text { D. Monty Wood, private collection, Ottawa, Ontario, Canada. } \\ \text { INBIO } & \text { Instituto Nacional de Biodiversidad, Santo Domingo, Costa Rica. } \\ \text { NMB } & \text { Naturhistorisches Museum Basel, Basel, Switzerland. } \\ \text { PHA } & \text { Paul H. Arnaud, Jr., private collection, San Francisco, California, USA. } \\ \text { USNM } & \text { National Museum of Natural History, Smithsonian Institution, Washington, DC, USA. }\end{array}$

\section{Lobomyia gen. nov.}

(Figs. 1-6)

Type species. Lobomyia neotropica Woodley \& Arnaud, by present designation.

Diagnosis. The combination of the following character states will diagnose Lobomyia: body with pale tomentose areas golden yellow (flies appearing metallic green in life); eyes sparsely to moderately haired; facial ridge mostly bare with only $2-5$ small setae above vibrissa; lower facial margin produced, visible in profile, extending beyond vibrissal bases; ocellar setae well-developed, proclinate; parafacial bare; genal dilation with pale hairs except for a few anteroventral major setae that are black; postpronotum with three setae nearly in a line, the middle seta only slightly displaced anteriorly; katepimeron bare; prosternum and much of pleura with white to pale yellow hairs; first postsutural supra-alar seta as long and stout as first postsutural dorsocentral seta; hind margin of hind coxa bare; at least mid and hind femora mostly yellow, usually all femora are yellow.

Lobomyia is most likely to be confused with Chrysoexorista Townsend, as individuals of this genus are also metallic green in life. However, Chrysoexorista species have more obviously pubescent eyes, the lower facial margin not protruding beyond the vibrissal bases, dark hairs on the prosternum and pleura, and dark femora.

Description. Coloration with tomentose areas metallic green in life, fading to dull golden-yellow upon drying.

Head (Figs. 1, 2). Eye sparsely to moderately haired; facial ridge slightly arcuate anteriorly in medial region, bare on most of its length, only 2-5 setae or hairs above vibrissa; lower facial margin produced, visible in front of vibrissal angle in lateral view; parafacial narrower than first antennal flagellomere, bare except for one or two small hairs below lowest frontal seta; gena well developed, about 1/5 of head height, with welldeveloped dilation; 3-6 setae in frontal row, only two arising below antennal bases, all inclinate or reclinate, posterior-most often reduced; female with two proclinate orbital setae, the posterior one reduced, about $1 / 2$ length of anterior; ocellar setae well developed, proclinate; outer vertical seta hairlike in male, essentially not differentiated from postocular setae, larger in female, but much smaller than inner vertical seta; male with base of the first flagellomere lobed in the type species (Fig. 1), unmodified in other known species; arista with first two segments very short, third segment slightly thickened on basal $2 / 5$; female antenna with first flagellomere shorter, not reaching oral margin, and without projecting lobe in all known species; palpus slender, nearly cylindrical.

Thorax. Postpronotum with three major setae in nearly a straight line, the angle formed by the slightly anteriorly placed middle seta with inner and outer setae greater than $160 \mathrm{E}$; notopleuron with 2 large setae; acrostical and dorsocentral setae $3+3$; first postsutural supra-alar seta as long and stout as first postsutural dorsocentral seta; scutellum with apical setae minute (Fig. 3), usually crossed apically but occasionally not 
crossed or absent, three other pairs of marginal setae well developed, one smaller pair of discal setae; proepisternum bare; prosternum setose with white hairs; katepisternum with 3 setae (sometimes 2, with anteroventral seta absent), the anteroventral seta arising close to the anterior one (Figs. 1,2); katepimeron bare; infrasquamal region bare; femora yellow; midtibia with one anterodorsal seta near middle and one smaller anteroventral seta slightly distal to it; hind tibia with anterodorsal setae forming a fairly evenly spaced row but the setae not closely spaced, with a single enlarged, medial seta; hind coxa bare posteriorly; bifurcation of vein $\mathrm{R}_{2+3}$ with 2-4 small setae; $\mathrm{M}$ ending at wing margin separately from $\mathrm{R}_{4+5}$; bend in $\mathrm{M}$ slightly obtuse.

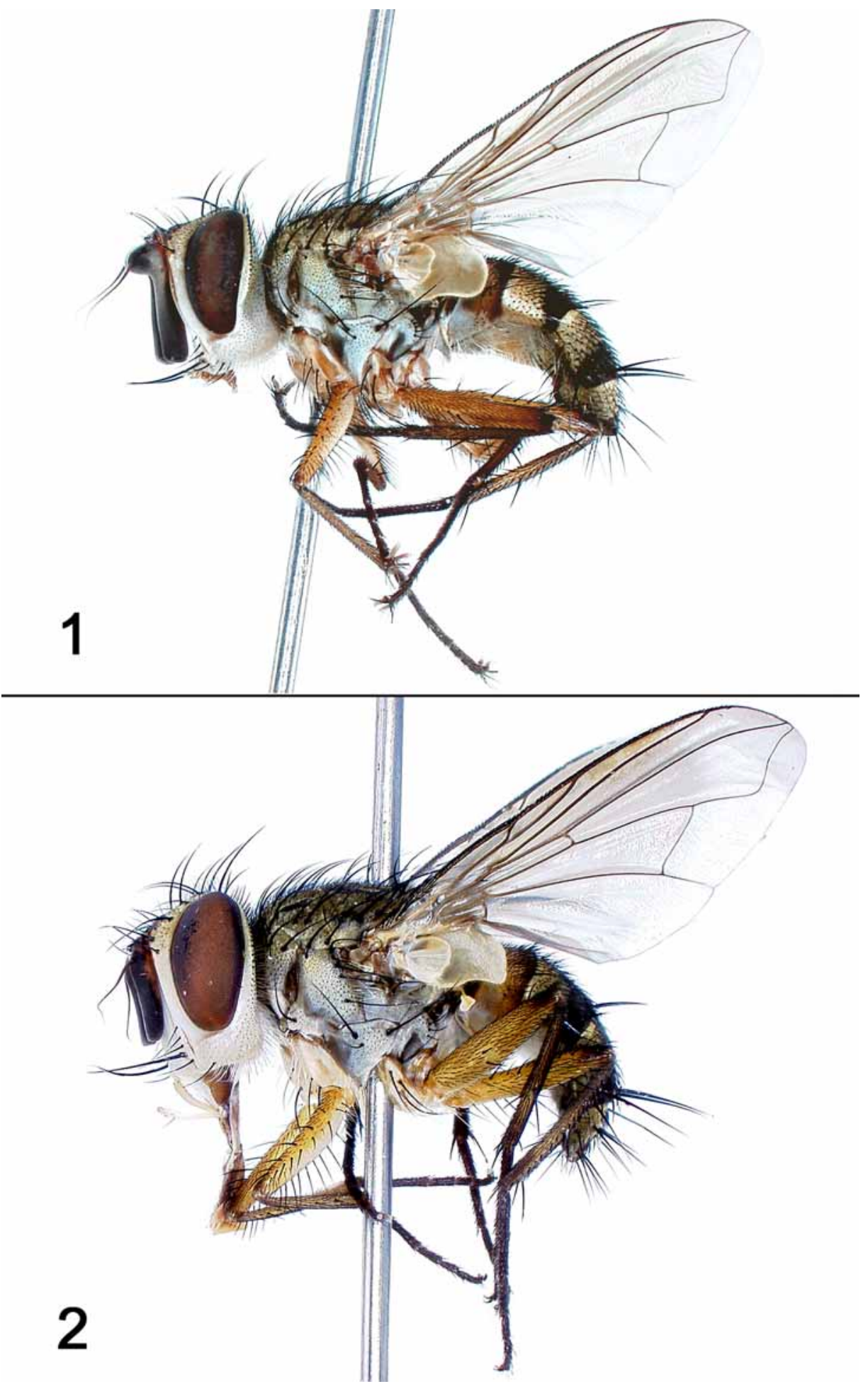

FIGURES 1-2. Lobomyia neotropica, gen. nov., sp. nov. 1, Male, lateral view. 2, Female, lateral view. 


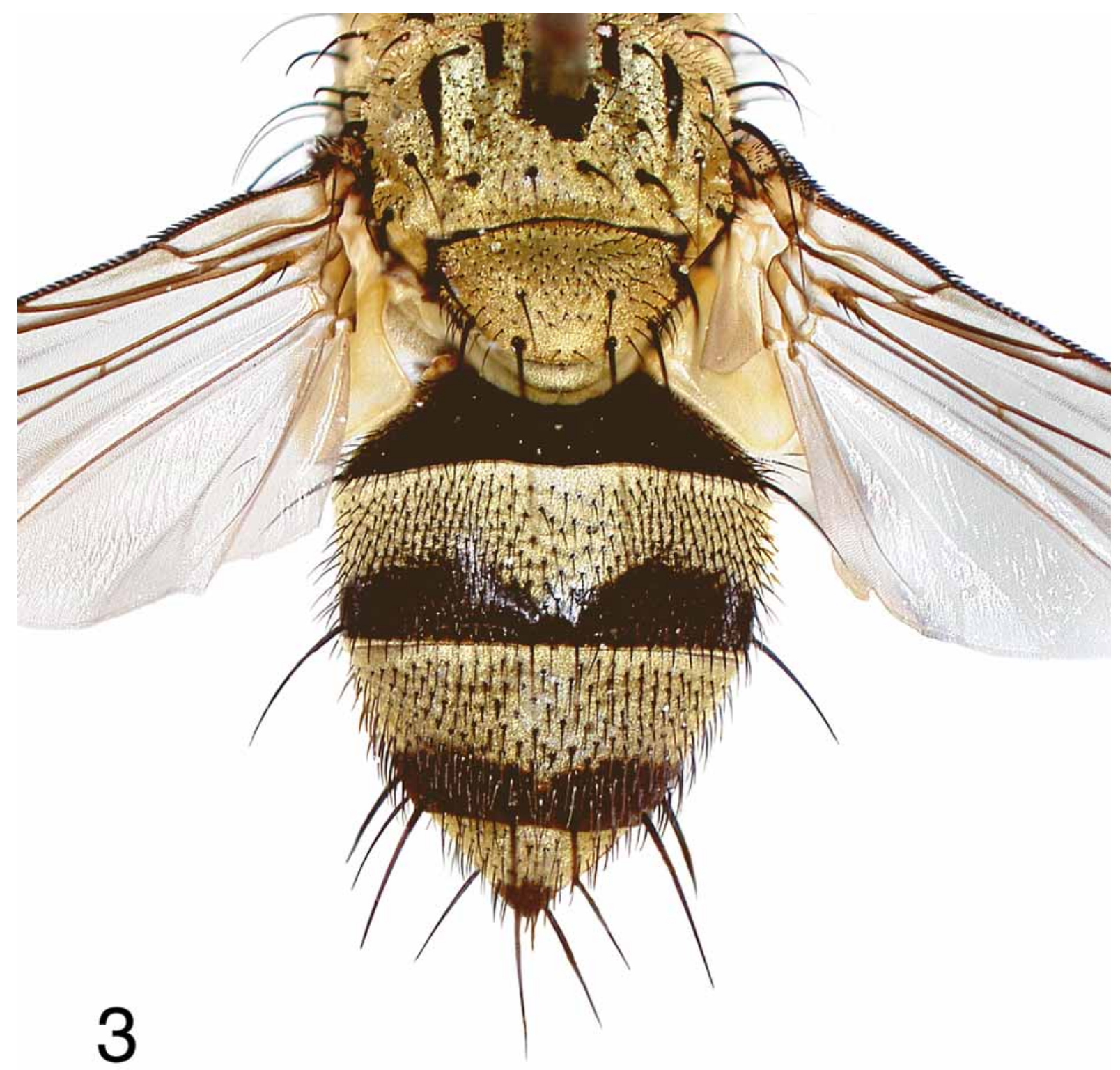

FIGURE 3. Lobomyia neotropica, gen. nov., sp. nov., dorsal view of female showing scutellar setation and abdominal color pattern.

Abdomen (Fig. 3). Median dorsal depression of tergite 1+2 extending to posterior margin, with one pair of median marginal setae; tergite 3 with one closely spaced pair of median marginal setae and no discal setae; tergite 4 with even row of marginal setae and no discal setae; tergite 5 with an even row of both discal and marginal setae.

Etymology. The generic name refers to the lobe at the base of the antennal flagellum in males of $L$. neotropica and is considered feminine in gender.

Remarks. Lobomyia belongs to the Exoristinae but does not show obvious affinities with any genus of Exoristinae with a strong first postsutural supra-alar seta. Eggs dissected from a wild-caught female (Nova Teutonia, Brazil) are about $0.30 \mathrm{~mm} \times 0.15 \mathrm{~mm}$ in size, yellowish, ovoid, without a strongly sclerotized chorion (as indicated by being somewhat collapsed when observed). Microtype eggs from a specimen of Chrysoexorista Townsend, on the other hand, were found to be $0.20 \mathrm{~mm}$ x $0.10 \mathrm{~mm}$, yellowish, and more 
strongly sclerotized. Also, no female specimen of Lobomyia was found with the abdomen appearing completely inflated by eggs, as is sometimes found in females bearing microtype eggs. Thus, the apparent presence of non-microtype eggs in Lobomyia indicates that the genus should possibly be placed in the tribe Eryciini. Behavioral observations are needed to confirm this beyond doubt. Lobomyia is not very similar to Chrysoexorista Townsend or other genera of Exoristinae that are metallic green in life, as these taxa all have more strongly developed apical scutellar setae and dark legs. Whether or not this metallic coloration has evolved multiple times in the Exoristinae will be determined only by more extensive phylogenetic study of the subfamily.

We have surveyed the extensive holdings of type material of Neotropical tachinids in USNM, a collection which contains the vast majority of types of C.H.T. Townsend, a prolific worker on the Neotropical fauna who described many of the genera found there. We did not find any specimens resembling Lobomyia neotropica, and therefore feel confident that Lobomyia is a generic-level taxon that is undescribed.

We are aware of two or three additional species that share all of the character states found in Lobomyia, except the expanded base of flagellomere one in males. We believe that these are congeneric. Given the vast Neotropical fauna of Tachinidae that is undescribed, it is likely that additional species will be discovered.

\section{Lobomyia neotropica, sp. nov.}

Description. Pale tomentose areas vivid metallic green in life, becoming mostly yellowish gray or goldenyellow after drying.

Male. Head below level of frons whitish tomentose contrasting to yellowish gold frontal region. Hairs on gena and back of head below middle white. Antenna with first flagellomere elongate, reaching oral margin, upper 1/4 with rounded lobe projecting about width of first flagellomere itself; antenna mostly dark, but inner surface of basal flagellomere with some yellowish coloration, occasionally a bit more extensive. Arista brown basally, black apically. Palpus pale yellow, nearly cylindrical.

Abdomen golden yellow tomentose, with distinct posterior markings as follows (Fig. 3): tergite 1+2 mostly black dorsally, the marking continuously narrowed ventrally; tergites 3 and 4 with a little less than posterior half black but these markings emarginate medially and continuously narrowed ventrally, so that the black appears more or less triangularly produced on each side; tergite 5 with small dorsoapical black spot. Setae and hairs on abdomen black dorsally, becoming white ventrally. Male terminalia as in Figs. 4-6 and in generic description.

Male terminalia. Fifth sternite (Fig. 4) broadly U-shaped, wider than long, typically with one large seta on each posterior lobe. Genital complex (Fig. 5) with ejaculatory apodeme large, fan-shaped. Pregonite elongate, pointed, apex sharp and minutely bent. Epiphallus present. Distiphallus with posterior portion slightly reflexed apically, anterior portion with slightly pointed, reflexed apex, with surface mostly denticulate. Surstylus elongate-triangular in posterior view (Fig. 6), quite broad in lateral view with very broadly rounded apex. Cerci in posterior view narrow, separated at apical $2 / 5$ of their length, apically rounded; in lateral view slightly sinuate with rounded apex bent anteriorly.

Length 6.0-7.2 $\mathrm{mm}$.

Female. Other than the dimorphism of the antennae and proclinate orbital setae noted in the generic description, there is very little difference between the two sexes. The tarsal claws are slightly shorter than in males, about $3 / 4$ the length of the fifth tarsomere.

Type material. The holotype male is labeled: "COLOMBIA: Antioquia, Caldas Oct 1973 Raúl Velez Angel ex: pupa of Glena bisulca (Geometridae)/ HOLOTYPE o Lobomyia neotropica Woodley \& Arnaud 2008". The holotype is deposited in USNM. 

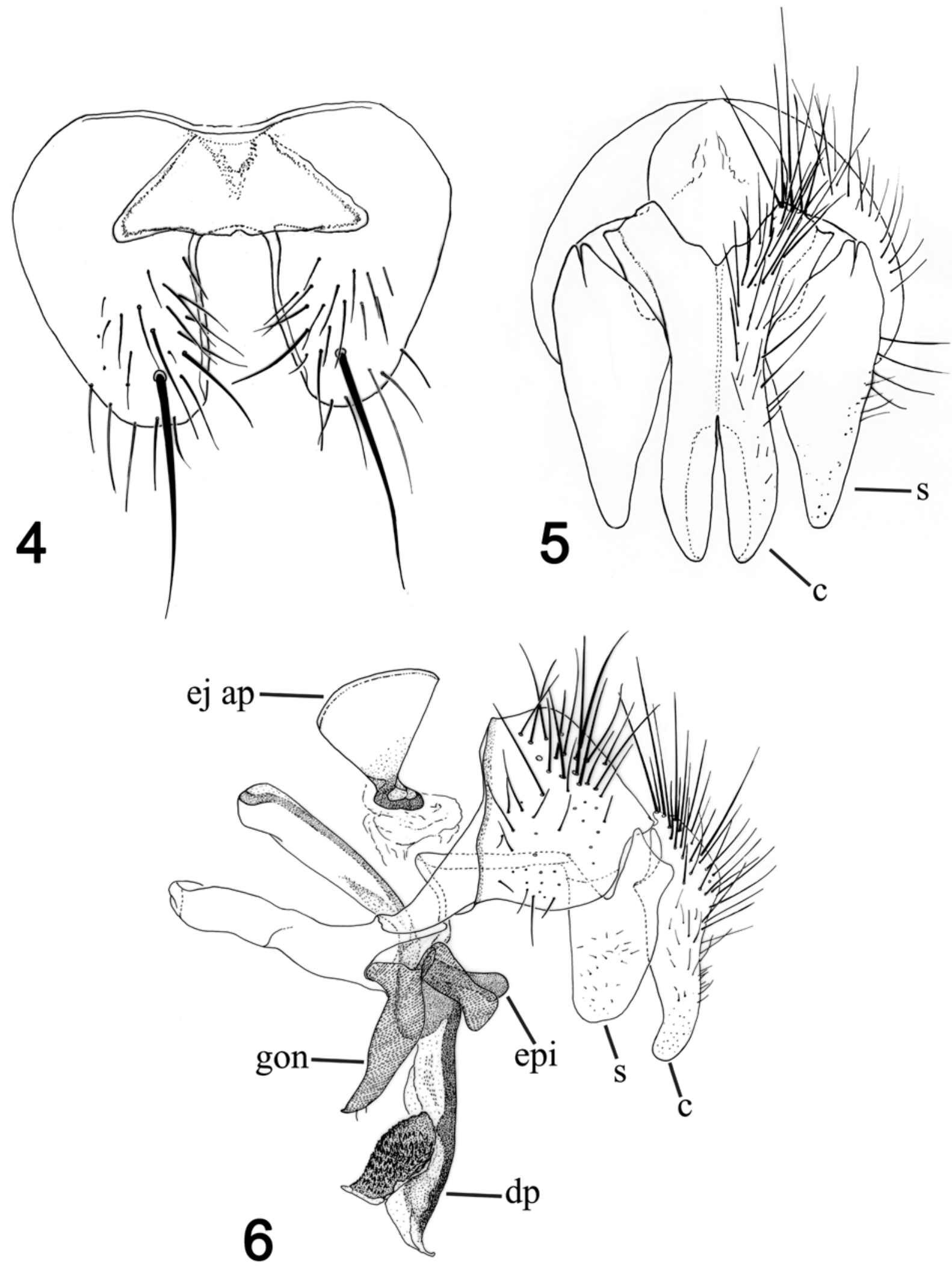

FIGURES 4-6. Lobomyia neotropica, gen. nov., sp. nov., male terminalia. 3, Fifth sternite, ventral view. 4, Genital complex, posterior view. 5, Genital complex, lateral view. Abbreviations: $c$, cercus. $d p$, distiphallus. ej ap, ejaculatory apodeme. epi, epiphallus. gon, pregonite. s, surstylus. 
Paratypes. BRAZIL: Santa Catarina, Nova Teutonia, $27^{\circ} 11^{\prime} \mathrm{S}, 52^{\circ} 23^{\prime} \mathrm{W}, 300-500$ meters, various dates ranging from 23 October - 1 May in the years 1955-1977, F. Plaumann (4 ox, 6 ㅇ CAS; 16 ox, 16 ㅇ CNC; 4 ox, 15 우 NMB; $160^{x}, 53$ 우 USNM; $80^{x}, 1$ 우 PHA; $20^{x}, 6$ 오 DMW). COLOMBIA: Antioquia, Caldas, October 1973, R. Vélez Angel, ex pupa of Glena bisulca (Geometridae) (1 $0^{\star}, 2$ ㅇ USNM); same data but July 1973 (2 $\sigma^{x}, 2$ ㅇ USNM); same data but 9 September 1969, A.E. Bustillo ( $2 \sigma^{x}$ USNM); same data but 8 April 1969 (2 $0^{x}, 2$ ㅇ USNM); same data but 28 July 1969 (1 ㅇ USNM); same data but 12 April 1973, T. Trivino, R. Gutierrez (1 9 USNM); Antioquia, Le Ceja, 19 May 1971, A.E. Bustillo, ex pupa of Glena bisulca (Geometridae) (3 o USNM); Antioquia, El Carmen de Viboral, 27 July 1972, A.E. Bustillo, ex pupa of Glena bisulca (Geometridae) (1 ox $^{x}$ ㅇ USNM); Atioquia, El Retiro, 11 August 1969, C. Rios, ex pupa of Glena bisulca (Geometridae) (2 $\sigma^{x}$ USNM); same data but 27 February 1970, A.E. Bustillo ( $10^{x}$ USNM); same data but 4 November 1970 (2 우 USNM); same data but 11 October 1971 ( $10^{x}, 1$ ㅇ USNM). COSTA RICA: Turrialba, 15-19 July 1965, P.J. Spangler (1 ㅇ USNM); Guanacaste Province, Estación Pitilla, 9 km S Santa Cecilia, 700m, L_N_329950_380450, March 1995, P. Rios (1 오 INBIO); Guanacaste Province, Macizo Miravalles, Estación Cabro Muco, 1100m, L_N_299769_411243, 24 September - 4 October 2003, J.D. Gutiérrez (1 ox INBIO); Guanacaste Province, Area de Conservación Guanacaste, Sector Cacao, Sendero Derrumbe, $10.929^{\circ} \mathrm{N}, 85.464^{\circ} \mathrm{W}, 1220 \mathrm{~m}$, gusaneros collectors, emerged from Dasylophia maxtla (Notodontidae), host collected 20 August 1997, parasites emerged 24 September - 7 October 1997 (4 우 CNC, Janzen voucher number 97-SRNP-1793); Guanacaste Province, Area de Conservación Guanacaste, Sector Cacao, Sendero Salto, $10.930^{\circ} \mathrm{N}, 85.469^{\circ} \mathrm{W}, 1000 \mathrm{~m}$, Mariano Pereira, emerged from Hemiceras deornata (Notodontidae), host collected 22 September 1998, parasite emerged 11 November 1998 (1 ㅇ CNC, Janzen voucher number 98SRNP-3736); Guanacaste Province, Area de Conservación Guanacaste, Sector Del Oro, Tangelo, $11.018^{\circ} \mathrm{N}$, $85.450^{\circ} \mathrm{W}, 410 \mathrm{~m}$, Roster Moraga, emerged from Hemiceras zula (Notodontidae), host collected 14 July 2001, parasites emerged 10-11 August 2001 ( $1 \circ^{x}, 1$ 우, CNC, Janzen voucher number 01-SRNP-9952); same data (1 $0^{\star}, 3$ ㅇ, CNC, Janzen voucher number 01-SRNP-9954); Guanacaste Province, Area de Conservación Guanacaste, Sector Cacao, Estación Cacao, $10.927^{\circ} \mathrm{N}, 85.468^{\circ} \mathrm{W}, 1150 \mathrm{~m}$, Freddy Quesada, emerged from Hemiceras pernubila (Notodontidae), host collected 25 August 2002, parasites emerged 8 November 2002 (2 $\circ$, CNC, Janzen voucher number 02-SRNP-23553); Puntarenas Province, Monteverde, 1500m, 20-22 August 1993 D.M. Wood (1 o DMW); Puntarenas Province, San Vito, Rio Jaba, $8^{\circ}$ 46'N, 82 57'W, 1100m, 24 January 1998, D.M. Wood (1 ๙ $^{\star}$ DMW); Puntarenas Province, Coto Brus, Estación Biológica Las Alturas, 1500m, L_S_522500_591300, M. Ramirez (1 $\sigma^{x}$ INBIO); Puntarenas Province, Camino a las Tablas, horilla de un charral, 1200m, L_S_318300_594400, 28 June 1998, E. Navarro (1 ox INBIO): same data but 27 August 1998 (1 $o^{x}$ INBIO); Puntarenas Province, San Luis Monteverde, Buen Amigo, 1000-1350m, L_N_250850_449250, August 1994, Z. Fuentes (1 ox INBIO); Puntarenas Province, Las Tablas, Sabalito, Cerro Quijada del Diablo, 2000m, L_S_317400_600800, 15 August 2000, M. Alfaro (1 o INBIO); Puntarenas Province, Cotoncito, 3.5 km N de la Lucha, 1600m, L_S_322100_597200, 4 July 1998, B. Gamboa (1 ox INBIO); Puntarenas Province, Send. El Eipario, 3 km NE Progresso, 1300m, L_S_319000_597000, 6-9 May 1997, E. Navarro, at light (1 우 INBIO); San José Province, Bijagualito, 638m, L_N_192300_477300, 9 February 1993, R. Guzmán (1 $o^{*}$ INBIO). MEXICO: Mexico, Ixtapan de la Sal, no date, S. P. Guillermo, on avocado flowers (1 $\sigma^{x}$ USNM). TRINIDAD: Simla, no further data ( $\left.10^{x} \mathrm{CNC}\right)$.

Distribution. Mexico south to southeastern Brazil (Fig. 7).

Etymology. The species epithet refers to the fact that this tachinid is widespread in the Neotropical Region. 


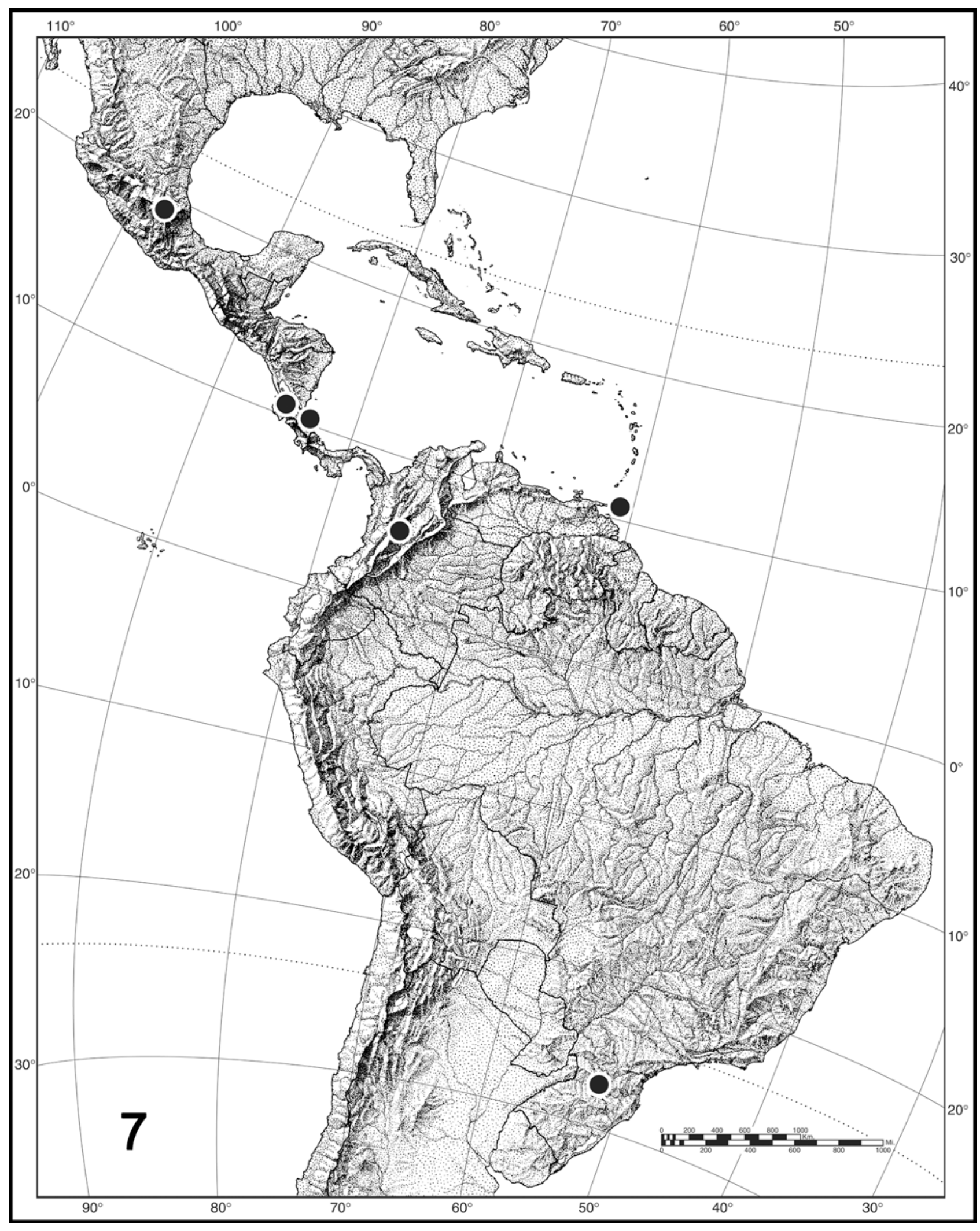

FIGURE 7. Distribution map of Lobomyia neotropica, gen. nov., sp. nov. Filled circles indicate known localities (except more localities are known from Costa Rica but are not indicated due to size constraints). 
Remarks. The distribution of Lobomyia neotropica is considerably wider than the known range of Glena bisulca (known from Colombia, Ecuador, and Venezuela), but is consistent with the known Neotropical range of the genus Glena (Rindge 1967). It therefore seems possible that other Glena species serve as hosts of $L$. neotropica. On the other hand, all of specimens reared by Daniel H. Janzen and coworkers at the Area de Conservación Guanacaste in Costa Rica were reared from species of Notodontidae (Hemiceras deornata Walker, H. pernubila Dyar, H. zula Schaus, and Dasylophia maxtla Schaus). Thus, the full range of hosts for L. neotropica is unknown at present.

\section{Acknowledgments}

Drs. James O'Hara and D. Monty Wood (CNC) and Michel Brancucci (NMB) made material available for our study. I am also very grateful to Dr. Daniel H. Janzen for providing specimens from his extensive rearing studies in Costa Rica, supported by NSF BS\&I Grant to D.H. Janzen NSF DEB 0515699. Inked illustrations were prepared by M.L. Cooley (Figs. 4-6). The automontage photographs were taken by Gary Ouellette, who also prepared the map and the plates. Charyn Micheli assisted in finalizing the plates for publication. We thank Irina Brake (formerly Smithsonian Institution), John Brown and Allen Norrbom for comments on the manuscript. We are grateful to all for their assistance which was invaluable toward completion of this project.

\section{References}

Drooz, A.T. \& Bustillo, A.E. (1972) Glena bisulca, a serious defoliator of Cupressus lusitanica in Colombia. Journal of Economic Entomology, 65, 89-93.

Kliejunas, J.T., Tkacz, B.M., Burdsall, H.H., Jr., DeNitto, G.A., Eglitis, A., Haugen, D.A. \& Zallner, W.E. (2001) Pest risk assessment of the importation into the United States of unprocessed Eucalyptus logs and chips from South America. General Technical Report FPL-GTR-124. U.S. Department of Agriculture, Forest Service, Forest Products Laboratory, Madison, Wisconsin. 134 pp.

McAlpine, J.F. (1981) Morphology and terminology - adults. In: McAlpine, J.F., Peterson, B.V., Shewell, G.E., Teskey, H.J., Vockeroth, J.R. \& Wood, D.M. (coordinators), Manual of Nearctic Diptera, Vol. 1. Agriculture Canada Monograph 27, Ottawa, pp. 9-63.

Rindge, F.H. (1967) A revision of the Neotropical species of the moth genus Glena (Lepidoptera, Geometridae). Bulletin of the American Museum of Natural History, 135, 107-172.

Vélez, R. (1974) El defoliador del cipres, Glena bisulca Rindge: 1972-3. Revista Facultad Nacional de Agronomia (Medellín), 19, 3-63.

Wood, D.M. (1987) 110. Tachinidae. In: McAlpine, J.F., Peterson, B.V., Shewell, G.E., Teskey, H.J., Vockeroth, J.R. \& Wood, D.M. (coordinators), Manual of Nearctic Diptera, Vol. 2. Agriculture Canada Monograph 28, Ottawa, pp. 1193-1269. 